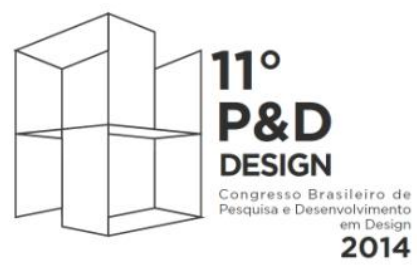

Gramado - RS

De 30 de setembro a 2 de outubro de 2014

\title{
“MEU CABELO NÃO É DE BOMBRIL!" - uma reflexão sobre como o racismo se apresenta no mundo da moda: caso Ronaldo Fraga e o cabelo de palha de aço.
}

\author{
Tatalina Oliveira \\ Faculdade Senac Pernambuco \\ tatitah@gmail.com \\ Rita de Cássia Nunes \\ Faculdade Senac Pernambuco \\ nunes.decassia@gmail.com \\ Bruna Liana Silva \\ Faculdade Senac Pernambuco \\ bruna.liana@yahoo.com.br
}

\begin{abstract}
Resumo: O polêmico caso do estilista Ronaldo Fraga e o cabelo de palha de aço, ocorrido no São Paulo Fashion Week (SPFW) de 2013, estimularam a necessária reflexão sobre a maneira como se dialoga com a estética negra (corpos e cabelos) no universo da moda. Sendo assim, este artigo objetiva trazer à tona a sensível discussão acerca do racismo nas passarelas. Para que isso se tornasse possível, procurou-se identificar a origem do comportamento racista e trazer seus reflexos para os dias atuais, tanto no aspecto social quanto no cultural, fazendo um contraponto com a função de comunicadora exercida pelo design de moda.
\end{abstract}

Palavras-chave: Racismo, Moda, Ronaldo Fraga.

Abstract: The controversial case involving the Brazilian stylist Ronaldo Fraga and the steel wool hair, occurred at São Paulo Fashion Week (SPFW) in 2013, stimulated the necessary reflection about the way the fashion universe dialogs with the black aesthetics (specially body and hair). Thus, this paper aims to bring up the sensitive discussion about racism in catwalks. To make it possible, we seek to identify the origin of the racist behavior and its reflexes to the present, in the social and cultural aspects, constructing a counterpoint with fashion design's communication function.

Keywords: Racism, Fashion, Ronaldo Fraga. 


\section{INTRODUÇÃO}

O São Paulo Fashion Week de 2013 (apresentação da coleção de verão 2014) foi um evento particularmente marcante. A razão para tal está no fato de o estilista Ronaldo Fraga apresentar sua coleção - com inspiração no Futebol de Várzea anos 1930, 40 e 50 , com beleza assinada por Marcos Costa. Era para ser uma homenagem ao povo negro, mas acabou por criar desconforto, sobretudo nas redes sociais, quando vários/as ativistas do Movimento Negro se pronunciaram acusando-o de racista devido à apresentação de modelos utilizando palha de aço em suas cabeças, simulando cabelo crespo, bem como pela sua justificativa pósevento.

Das discussões a respeito do caso, viu-se a necessidade de abordar esta temática de modo mais sistemático, para além dos meios digitais (blogs, por exemplo), trazendo-a para a academia. Vislumbrou-se uma oportunidade para discussões que fizessem uma ligação, para além de reflexão, sobre moda e a cultura e estética negras. Para tal, foi criada na Faculdade Senac Pernambuco, um grupo de pesquisa, ainda no mesmo ano (2013), chamado Conhecendo o Estado de Pernambuco: um mapeamento do movimento e cultura negra, com o intuito maior de trazer ao campo da moda reflexões acerca de racismo, estereótipos, valorização e cuidados da beleza negra (além de uma maior compreensão sobre o significado de ser negro), objetivando, também, a produção de padronagens, estampas e modelagens que valorizem esta estética.

Gostar-se-ia de deixar claro que não há desejo de criar juízos de valor sobre o estilista e sua equipe, mas trazer à luz da reflexão como determinadas atitudes, aparentemente inocentes, podem trazer consigo uma carga de racismo bastante forte, mesmo que a intenção do autor do ato tenha sido destituída de qualquer objetivo ofensivo.

Outra questão inerente a este material é refletir aspectos sociais e culturais da sociedade brasileira (sobretudo os aspectos étnico-raciais) e em como eles se refletem e se apresentam no campo da moda. É importante frisar que, quando se trata dos aspectos pluralistas do conceito de cultura, esta "é uma descrição de um modo particular de vida que exprime certos significados e valores, não só na arte e no saber, mas também nas instituições e no comportamento habitual" (WILLIAMS, 1961 apud BARNARD, 2003, p. 61). Williams (1961, apud BARNARD, 2003, p. 63) acrescenta: "a cultura é o sistema significante através do qual... uma ordem social é comunicada, reproduzida, experimentada e explorada".

O racismo no Brasil é um assunto delicado, e que ainda é tratado com bastante melindre, sobretudo para não se criar desconforto. Embora se acredite que tenha 
surgido a partir da escravização dos povos africanos, retirados à força de seus países para trabalhar como mão de obra nas lavouras e nas Casas Grandes, suas origens revelam-se muito mais antigas (MOORE, 2007).

Segundo Moore (2007), o processo de segmentação humana a partir do fenótipo (povos meladonérmicos, de pele escura, versus povos leucodérmicos, de pele clara) é muito antigo, e tem como principais expoentes as sociedades gregas e romanas, as quais costumavam nutrir aversão a pessoas possuidoras de pele escura, chegando inclusive a criar estudos a respeito das características físicas e o modo como influenciavam os traços de personalidade. Sabe-se que embates por territórios também estão envolvidos no processo, chegando a criar o que o autor chama de simbologização do que seria o racismo como algo "natural", sobretudo nos grandes livros sagrados de religiões como hinduísta, católica etc.

O racismo apresenta-se de várias formas, uma delas é através do processo de uma maioria subjulgar uma minoria (frisa-se que aqui não se trata de números, mas de poder econômico e social). Tal fato pode ocorrer por meio de estereótipos (GOMES, 2002; ROSO et. al, 2002), que acabam por ser fortemente reafirmados em piadas em momentos de comensalidade, nas propagandas dos grandes veículos de comunicação, e que possuem, senão, o objetivo de contribuir para a manutenção de uma ordem social (HALL, 1997, apud ROSO et. al, 2002).

Assim, apresentar modelos com palhas de aço em suas cabeças intencionando homenagear os negros e negras, fez com que o estilista e o maquiador de sua equipe tocassem num ponto neovrálgico da população negra e afrodescendente, visto que seus traços físicos como cor da pele, nariz, textura de cabelo são alvo de constantes piadas, atuando como um obstáculo à construção de sua auto estima e à aceitação de sua beleza.

Vive-se num país que possui, em sua maioria, população negra e mestiça, mas que toma como cânone de beleza o padrão europeu de cor de pele, olhos e textura de cabelos, e que se torna bastante visível quando se põe os olhos nas passarelas dos grandes eventos de moda. Não se nasce negro, torna-se negro. Trata-se de uma questão de resistência.

\section{O RACISMO E SUAS ORIGENS PELAS LENTES DE CARLOS MOORE}

Do século XV até os dias atuais, o fenômeno do racismo fora lido de maneiras diversas entre as sociedades. Se por volta do século XV, ele era entendido como uma segmentação dos diferentes povos em raças, divididos em categorias e espécies, através de uma determinação biológica, (MOORE, 2007, p. 21), hoje por meio de mudanças políticas, econômicas e, sobretudo, científicas que negam a existência biológica de "raças humanas", o racismo pode ser lido como um processo de 
hierarquização socioeconômica e cultural baseada nas características fenotípicas dos indivíduos. O fenômeno continua encravado na sociedade influenciando na construção das relações de superioridade e inferioridade entre diversos grupos.

Pode-se dizer que a ideia de superioridade e inferioridade apresentada por essa leitura atual do racismo tem suas bases no pensamento greco-romano. Os povos da antiguidade clássica apresentavam em seu comportamento a aversão a estrangeiros e desse modo, desenvolveram teorias que os diferenciavam moralmente de indivíduos que habitavam outras regiões e possuíam características físicas diferentes. O raciocínio considerado científico na época fazia uma leitura de personalidade a partir da análise da anatomia humana. Frequentemente características fenotípicas de povos africanos eram apontadas como negativas, enquanto que traços físicos do homem europeu eram tidos como positivos ou superiores (MOORE, 2007).

Direcionando a análise do racismo para a segmentação humana a partir do fenótipo, como sugere Moore (2007), é possível perceber que o racismo é um fenômeno que aconteceu e continua acontecendo em diversas esferas sociais, culturais, políticas, econômicas e geográficas, desde os mais remotos tempos. Para o autor, a partir dos movimentos de migrações ocorridos no final do período neolítico, houve encontros entre povos meridionais (de cor escura) e setentrionais (de cor clara), que não possuíam conhecimento um dos outros, culminando em conflitos prolongados e traumáticos pela posse dos recursos. Tais embates resultaram na criação de uma nova ordem social baseada em conceitos raciológicos, pautados na relação entre ocupações e invasões territoriais e das características fenotípicas que cada grupo possuía.

Ainda sobre o mesmo ponto de vista, esses conflitos desdobraram-se para a esfera do simbólico, sofrendo um processo denominado, por ele, de simbologização:

\begin{abstract}
Estabelecemos uma diferença entre uma realidade simbólica, representação imaginada que o ser humano reconhece como sendo de sua criação, e uma representação simbológica, representação imaginada que emerge de uma reformulação distorcida dos próprios símbolos. Simbologização refere-se aos processos mediante os quais essas reformulações são operadas até constituir um novo imaginário coletivo; esse último passando a ter vida autônoma, constituindo-se numa nova realidade já não reconhecida pelo ser humano como sendo de sua própria autoria. Essa perda de "memória autoral" permite que a nova realidade imaginada possa chegar a governá-lo (MOORE, 2007, p. 244).
\end{abstract}

De acordo com suas ideias, mesmo com os avanços científicos no campo da genética e estudos biológicos, há, ainda, no inconsciente coletivo a ideia de raça como elemento caracterizador das condições de "ser humano" dos indivíduos. Moore (2007, 
p. 38) afirma: "Raça não é um conceito que possa ser definido segundo critérios biológicos. Porém raça existe: ela é uma construção sociopolítica".

Compreender como se deu esse processo de construção sociopolítica da ideia de raça, e consequentemente, dos princípios racistas é fundamental para analisar o racismo e seus desdobramentos na atualidade. A partir dos estudos de Moore (2007), como já mencionado, houve na história da humanidade, o processo de simbologização dos embates ocorridos entre os povos melanodérmicos (negros) e leucodérmicos (brancos) e, posteriormente, a assimilação desses conflitos para as narrativas míticas e religiosas sobre a existência humana - que perduram até os dias atuais.

Moore (2007) corrobora sua ideia sugerindo uma análise de textos sagrados dos povos euro-semitas, do Oriente Médio e da Ásia Meridional. Ele direciona-se à análise do Rig-Veda (livro sagrado indiano), extraindo trechos que comprovam como as lutas por território, recursos, poder e riquezas possuíam um "caráter abertamente racial" e como contribuíram para a criação de uma visão "negrofóbica em escala mundial" (MOORE, 2007, p.51-50).

\footnotetext{
Assim, o Rig-Veda relata que Indra, suposto líder dos invasores arianos, logo transformado em semi-Deus, ordenou seus súditos guerreiros para "destruir o dasyu" e eliminar a pele negra da face da Terra. O Rig-Veda, que descreve os grandes combates entre esses brancos e os autóctones negros em termos de uma luta entre a "luz" e as "trevas", diz, textualmente que "Indra matou os bárbaros de nariz chato (anasha)" e "assoprou com força sobrenatural, fazendo desaparecer da terra e dos céus a pele negra que Indra tanto odeia" (MOORE, 2007, p. 51)
}

O racismo quando visto sob essa ótica, desvalida a ideia de seu surgimento estar associado apenas ao processo de escravidão dos povos africanos, mas amplia o leque de possibilidades e consequentemente, de compreensão de um dos maiores problemas da humanidade. A seriedade da transferência de conflitos reais para a esfera do simbólico apesar de assustadora dá-nos subsídios suficientes para o entendimento sobre a persistência do fenômeno nas sociedades atuais.

A gênese do fenômeno conhecido hoje como racismo pode efetivamente ter sido aquém dos últimos quatro ou cinco mil anos da nossa história, como resultante de longínquos conflitos concretos, em torno da posse de recursos entre povos nômades invasores e povos agrícolas sedentários, já fenotípica e culturalmente diferenciadas. Essa interpretação ganha sustentação no exame das Escrituras fundadoras de diversas religiões: judaísmo, cristianismo, islamismo e hinduísmo, nas quais repetidas vezes fazem referências a uma "maldição" divina da "pele negra" (MOORE, 2007, p. 245).

Considerando que grande parte do Ocidente partilha da mesma estrutura religiosa - o cristianismo - e de acontecimentos históricos como a escravidão dos povos africanos, há na contemporaneidade uma considerável manifestação do racismo, que 
parece enraizar-se e camuflar-se cada vez mais através do "mito da democracia racial" $^{1 "}$ e de práticas discriminatórias corriqueiras consideradas "normais" pelos indivíduos que as praticam e muitas vezes, pelos indivíduos negros/mulatos que são as vítimas. Moore (2007) nomeia essa situação como sendo o "Racismo Velado". O racismo dos dias atuais, o que passa na televisão, nas propagandas, nas filas de bancos, restaurantes e nas passarelas. Aquela ação discriminatória em que muitas vezes somos os praticantes e difusores, mas não nos damos conta até sermos as vítimas.

\section{SOBRE ESTEREÓTIPOS}

Ano de 2013, evento: São Paulo Fashion Week (SPFW). Ronaldo Fraga, renomado estilista brasileiro, desfila sua coleção de verão 2014, com inspiração no futebol dos anos 1930, 40 e 50. Tudo estaria perfeito, se não fossem duas razões: as perucas feitas de palha de aço utilizadas pelas modelos e a frase proferida pelo estilista: "Pedi para o Marcos Costa: quero um cabelo ruim. As meninas são lindas, mas com Bombril na cabeça. Ninguém aqui vai alisar o cabelo" ${ }^{2}$.

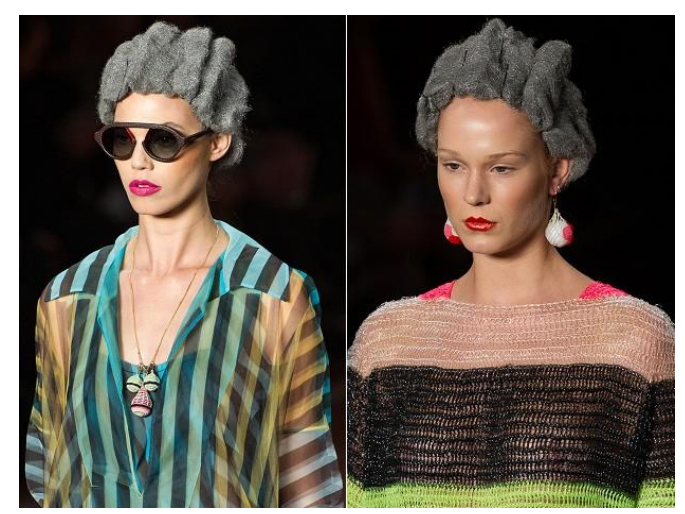

Figura 1: "Desfile Ronaldo Fraga". Fonte: Portal de Notícias G1. Foto: AFP PHOTO / YASUYOSHI CHIBA. Acesso em: 09/03/2014, às $16 \mathrm{~h} 50$

\footnotetext{
${ }^{1}$ Trata-se da crença na convivência harmoniosa entre brancos e negros, a partir do fim da escravidão. Fontes: $\quad$ http://ffw.com.br/desfiles/sao-paulo/verao-2014-rtw/ronaldo-fraga/789826/default, http://www.24horasnews.com.br/noticias/ver/acusado-de-racismo-maquiador-do-desfile-de-ronaldofraga-nega-intencao-discriminatoria.html
} 


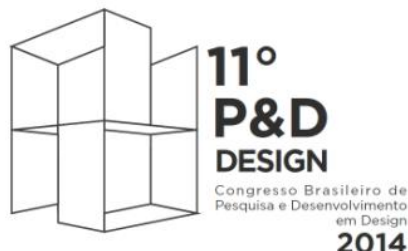

Gramado - RS

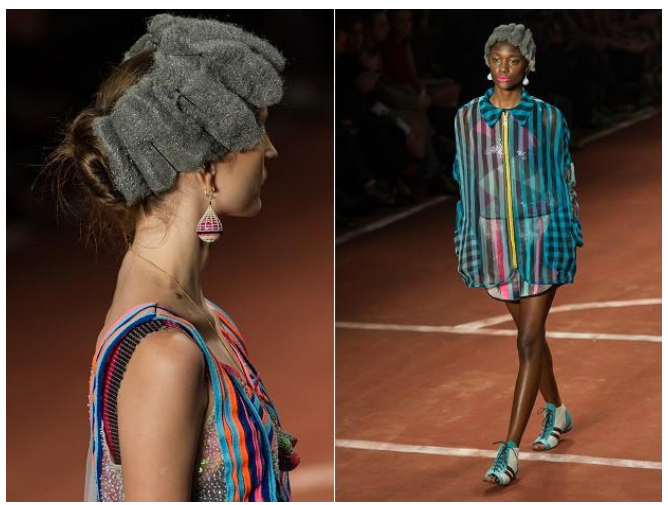

Figura 2: "Desfile Ronaldo Fraga". Fonte: Portal de Notícias G1. Foto: AFP PHOTO / YASUYOSHI CHIBA. Acesso em: 09/03/2014, às 16 h50

"O nosso cabelo crespo não é ruim!", gritam as/os diversas/os negras/os militantes em variados blogs da web $^{3}$ quando analisam o desfile de Ronaldo Fraga, com beleza das modelos assinada por Marcos Costa, que se defende e ao estilista, em entrevista a um portal de grande visibilidade:

\begin{abstract}
"Nunca foi minha intenção ou de Ronaldo Fraga ofender ou discriminar quem quer que seja. A ideia para o look do desfile era ressaltar a beleza de cabelos que podem ser moldados como esculturas, não importando o fato de serem crespos. Depois de testarmos alguns materiais, o Ronaldo Fraga sugeriu a palha de aço. Foi também uma forma de subverter um preconceito enraizado na cultura brasileira. Por que o negro tem de alisar seus fios? Eles são lindos!" (24 HORAS NEWS, 2013)
\end{abstract}

Temas sobre a representação negra e sua relação com seus corpos começam a ser amplamente discutidos nos meios midiáticos e consideramos de extrema relevância ampliar essa discussão, sobretudo no que tange ao campo da moda, visto que se trata de um grande disseminador de padrões estéticos, muitas vezes ditatoriais, e passível de ampla reflexão sobre sua forte ligação com questões sociais, econômicos, políticas e culturais.

A ligação do negro com o seu corpo é complexa e, pode-se dizer, que construída dia a dia. É necessário compreender as formas simbólicas as quais homens e mulheres, jovens e adultos constroem sua identidade, pois não se trata de uma relação que se circunscreve apenas ao espaço da casa e da família, da militância ou o círculo de amizades e relacionamentos afetivos.

3 http://machismochatodecadadia.tumblr.com/post/45851532088/ronaldo-fraga-bombril-e-cadiveu-oque-eles-tem-em\#.UxzHE IdWSo, http://meninasblackpower.blogspot.com.br/2013/03/nao-nos-naotemos-o-cabelo-de-bombril.html, $\quad$ http://blogueirasfeministas.com/2013/03/racismo-pouco-ebobagem-desfile-ronaldo-fraga/. Acesso em 09/03/2014, às $16 \mathrm{~h} 53$. 


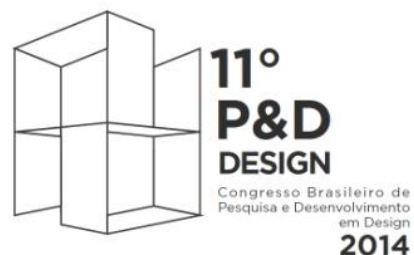

Gramado - RS

2014

De 30 de setembro a 2 de outubro de 2014

De acordo com Gomes (2002),

o corpo fala a respeito do nosso estar no mundo, pois a nossa localização na sociedade dá-se pela sua mediação no espaço e no tempo. Estamos diante de uma realidade dupla e dialética: ao mesmo tempo que é natural, o corpo é também simbólico (GOMES, p.41, 2002).

Desta forma, o olhar do negro sobre seu corpo sofre diversas influências: segundo Gomes (2003, p. 2), a identidade negra é "um processo que não se dá apenas a começar o olhar de dentro, do próprio negro sobre si mesmo e seu corpo, mas também na relação com o olhar do outro, do que está fora". Para o sujeito que o possui, o cabelo crespo além de forte marca identitária, muitas vezes pode vir a agir como marca de inferioridade, demonstrando, assim, o complexo sistema simbólico que gira em torno da temática.

Roso et. al. (2002) afirmam que "uma relação de dominação pode ser estabelecida de diversos modos", podendo constituir-se no campo do gênero, da classe, da raça etc., e seu resultado acaba sendo um agravamento do processo de exclusão, pois seu direito à cidadania acaba por lhe ser minimizado. E, para que seja possível compreender o desgaste entre a comunidade negra e o estilista Ronaldo Fraga em decorrência de seu desfile, torna-se mister entender que no Brasil vive-se o binômio da maioria e da minoria, e que além dos termos serem interdependentes, 0 primeiro caracteriza-se por possuir a maior parte dos recursos econômicos, de status e de poder, estabelecendo uma relação injusta com as minorias sociais (mesmo que em número sejam maiores).

Minoria (assim como maioria) não tem a ver, pelo menos para nosso estudo, com questões numéricas. Por exemplo, nosso país é constituído por um número expressivo de mulatos/as e negro/as, mas eles/as são minorias, pois são constantemente depreciados, discriminados e excluídos (ROSO et. al., 2002, p. 77).

A experiência corporal acaba por ser modificada pela cultura a que se faz parte, e para muitos negros e negras, o seu corpo (nariz, boca, cor da pele, textura do cabelo, volume e forma) funciona como suporte de sua identidade, ultrapassando as barreiras da estética, alcançando uma representação política fortíssima.

"Ser negro é uma questão de resistência", como citou Costa (2009) em Fala, Crioulo: o que é ser negro no Brasil, e para muitos negros/as brasileiros/as, amar-se como tal (e reconhecer-se como belo/a) é um processo lento e doloroso, que se dá aos poucos e diariamente, sobretudo no que tange ao cabelo, por ser o elemento mais visível de sua identidade. 
Possuir o cabelo crespo ou cacheado é ter de passar por dificuldades, ainda dentro de casa, ao arrumá-lo (visto que a muitos familiares falta paciência para penteá-los ou devido à resistência de mantê-los livres e soltos devido à praticidade), ou ainda na escola, quando se dá o contato dessas crianças com outro universo que não o seu circulo de convivência familiar diária, para além de outros contextos de comensalidade, em que têm de ouvir e interiorizar piadas e brincadeiras (argumentadas como inofensivas e sem o objetivo de serem pejorativas) a respeito da textura de seus fios.

"Cabelo de Bombril", "fuá", "cabelo de piaçava" são apelidos que Ihes são conferidos e apenas expressam a simbologia de inferioridade pela qual o negro é visto em uma sociedade em que o racismo atua de maneira velada e, muitas vezes, em tom de brincadeira. "Nessa relação de opressão, os estereótipos surgem e se cristalizam" (ROSO et. al. , 2002, p. 78).

Como discute Hall (1997), estereotipar faz parte da manutenção da
ordem social, estabelecendo uma fronteira entre o "normal" e o
"desviante", o "normal" e o "patológico", o "aceitável" e o
"inaceitável", o que "pertence" e o "que não pertence", o "nós" e o
"eles". Estereotipar reduz, essencializa, naturaliza e conserta as
'diferenças', excluindo ou expelindo tudo aquilo que não se
enquadra, tudo aquilo que é diferente (ROSO et. al., 2002, p. 78).

Apesar de se afirmar que o Brasil vive uma democracia racial, o país possui uma população em que sua grande maioria é formada por negros e mestiços, mas que seu padrão de beleza ideal é o europeu: cabelos lisos e contidos, nariz afilado, lábios finos (GOMES, 2012). Os apelidos marcam a história dos/as negros/as, sendo suas primeiras experiências públicas de rejeição ao corpo, além de expressarem que a estética negra é vista como símbolo de inferioridade, sempre associada a objetos e artefatos artificiais, tal como palha de aço, piaçava etc. (GOMES, 2002).

Assim, palavras, frases, imagens, ou piadas, seriam inofensivas se não carregassem ideologia consigo, "se não estivessem promovendo interesses de grupos de pessoas que, consciente ou inconscientemente, discriminam aqueles/as que são minoria" (ROSO et. al., 2002, p. 80).

Ao apresentar suas criações em um evento de grande porte como SPFW (em 2013) exibindo os cabelos feitos de palha de aço, Ronaldo Fraga e Marcos Costa corroboram com um estado de zombaria (que carrega consigo o peso do preconceito que abala a auto estima de tantos negros/as) acerca do que não preenche a lacuna do que se considera belo num país que se orgulha em exaltar o ritmo e a cultura negra, mas que nega suas características fenotípicas.

O cabelo e o discurso apresentados na passarela pelo estilista e equipe, trazem consigo uma representação estética negativa e despolitizada, que não faz jus à história 
e à luta da comunidade negra por maior visibilidade e representatividade. Analisando ponto a ponto a justificativa de Ronaldo Fraga, percebem-se quantos adjetivos e conceitos pejorativos ela carrega consigo:

"Pedi para o Marcos Costa: quero um cabelo ruim. As meninas são lindas, mas com Bombril na cabeça. Ninguém aqui vai alisar o cabelo".

a. Categorização do cabelo crespo como uma textura ruim, apresentando-se como uma manifestação da negrofobia sugerida por Moore (2007);

b. "Modelos lindas", mas que devem possuir "Bombril" na cabeça. Sugerindo que a relação entre o ter características fenotípicas afrodescendentes estivesse dissociada do que se considera belo;

c. Apresentação do "crespo" a partir da associação à palha de aço resgata as relações pejorativas à textura e volume dos fios, vividos ainda na infância por indivíduos/as negros/as.

Em resumo, este discurso é capcioso, pois considerar como "ruim" uma textura tão própria da comunidade negra e afrodescendente, e que foge por completo do que é considerado belo num país como o Brasil, aponta que ainda é necessário percorrer um longo caminho contra o racismo e suas manifestações. Neste sentido, faz-se imperioso reforçar que sendo moda comunicação, carrega consigo ideologias e discursos que não se isentam da responsabilidade de perpetuar o processo de simbologização e seus conceitos.

\footnotetext{
Uma coleção não apenas possui o termo safári, ou aviação, ou oriente, ela é hoje analítica, reflexiva, contestadora e autocontestadora, espaço para discussão da vivência da rua; ela não copia a realidade, mas se comunica, discute, vive e a rearticula. Tal qual a antropologia pós-moderna ou reflexiva - que produz uma discussão sobre si mesma, a moda da era pós-industrial é autocrítica, auto-reflexiva, aberta ao pensar e ao sentir, e seu corpus é comunicação desta vivência sensorial e intelectual (BRANDINI, 2007, p. 31).
}

É necessário que se entenda o alcance das mensagens transmitidas pelo sistema da moda, para além das passarelas (sobretudo). Trazer esse tipo de reflexão à tona é contribuir para uma moda mais crítica e acessível a outras belezas e olhares além dos cânones já (pré)estabelecidos, como o da beleza branca e europeizada, possibilitando uma maior representatividade e espaço para tantos jovens negras/os.

\section{CONCLUSÃO}


A moda contemporânea, sobretudo as de designers de vanguarda, tornou-se objeto de grande expressividade, transmitindo significados, além de ser objeto de arte e comunicação. Segundo Brandini (2007, p. 25), "para além de simples vestimenta, o sistema de moda serve à função de expressão e de representação das relações sociais entre indivíduos, culturas, políticas, manifestações que tomam a urbe como espaço de experiência".

Precisa-se compreender que a moda expressa a forma como indivíduos e coletividade sentem e manifestam seus estilos de vida, bem como toda dinâmica social. Deste modo, quando o desfile de um evento que conferiu ao Brasil uma notoriedade mundial no mercado de moda, como o SPFW, ocorre, precisa-se entender que ele não apenas existe para representar o que estará nas vitrines da próxima estação, mas também para trazer à tona tudo que é inerente ao sistema de moda: desde tendências têxteis, tecnológicas e mercadológicas, até sociais e culturais.

Quando negro/as militantes fazem repercutir suas opiniões acerca do que consideram ofensivo nas passarelas, ou quando manifestam-se em busca de maior representatividade em um meio que exerce grande influência em tantos jovens, tentam mostrar que já não há mais espaço para perpetuação de conceitos e atitudes racistas, mesmo que sem real intenção de ferir. $\mathrm{O}$ uso de estereótipos nas mídias e nas passarelas é muito comum, e só representam uma tentativa de manter de pé a fronteira entre o normal, aceitável e belo e o desviante, inaceitável e feio.

Desejou-se neste artigo propor um exercício intelectual, passível de penetração nas várias esferas do sistema de moda. Propôs-se, deste modo, uma ampla reflexão acerca dos diversos significados que estão envolvidos nas várias etapas de criação de coleções que vão às passarelas (planejamento, produção e comercialização). Se não forem muito bem planejados e discutidos, tornar-se-ão canais para a perpetuação de conceitos imersos em preconceito, que se apresentarão nas passarelas, nas lojas e, sobretudo, no imaginário dos consumidores.

\section{REFERÊNCIAS}

BARNARD, Malcolm. Moda e Comunicação. Rio de Janeiro: Rocco, 2003.

Blogueiras Feministas. Mar. $2013 . \quad$ Disponível em: http://blogueirasfeministas.com/2013/03/racismo-pouco-e-bobagem-desfile-ronaldofraga/. Acesso em: 09 mar. 2014.

BRANDINI, Valéria. Vestindo a Rua: moda, comunicação e metrópole. Revista Fronteiras - estudos midiáticos. Vol. IX, no. 1, - jan/abril 2007, pp. 23 - 33. 
COSTA, Haroldo. Fala, Crioulo: o que é ser negro no Brasil. Rio de Janeiro: Record, 2009.

Fashion forward. N. 789826, mar. 2013. Disponível em: <http://ffw.com.br/desfiles/sao-paulo/verao-2014-rtw/ronaldofraga/789826/default>. Acesso em: 09 mar. 2014.

GOMES, Nilma Lino.Trajetórias escolares, corpo negro e cabelo crespo: reprodução de estereótipos ou ressignificação cultural. Rev. Bras. Educ. [online]. 2002, n.21, pp. 4051. ISSN 1413-2478.

- Corpo e Cabelo como Símbolos da Identidade Negra. In. II Seminário Internacional de Educação Intercultural, Gênero e Movimentos Sociais: Identidade, Diferença e Mediações. Santa Catarina: UFSC. Abril, 2003.

G1 Globo. Mar. 2013. Disponível em: <http://g1.globo.com/poparte/noticia/2013/03/desfile-de-ronaldo-fraga-com-cabelo-bombril-divideopinioes.html>. Acesso em: 09 mar. 2014.

Machismo Chato de Cada dia, n. 45851532088, abr. 2013. Disponível em: < http://machismochatodecadadia.tumblr.com/post/45851532088/ronaldo-fragabombril-e-cadiveu-o-que-eles-tem-em\#.UxOFQPIdWSp>. Acesso em: 09 mar. 2014.

Meninas Black Power, mar. 2013. Disponível em: < http://meninasblackpower.blogspot.com.br/2013/03/nao-nos-nao-temos-o-cabelode-bombril.html>, Acesso em: 09 mar. 2014.

ROSO, Adriane et. al. Cultura e Ideologia: a mídia revelando estereótipos raciais de gênero .Psicol. Soc. [online]. 2002, vol.14, n.2, pp. 74-94. ISSN 1807-0310.

24 Horas News. Mar. $2013 . \quad$ Disponível em: <http://www.24horasnews.com.br/noticias/ver/acusado-de-racismo-maquiador-dodesfile-de-ronaldo-fraga-nega-intencao-discriminatoria.html>. Acesso em: 09 mar. 2014. 